\title{
Metabolic Inertia in Contracting Skeletal Muscle: The Expanding Role of the Carnitine Pool
}

\author{
Paul A. Roberts* \\ Institute of Clinical Pharmacology \& Toxicology, Department of Research, \\ University Hospital Basel, Switzerland
}

Received October 18, 2004; accepted November 25, 2004

Published online July 18, 2005 C) Springer-Verlag 2005

\begin{abstract}
Summary. The ability of the muscular carnitine pool to accept and temporally donate acetyl groups (from and towards the coenzyme A pool) is an important functional role of carnitine within biological systems that is often overlooked within the scientific literature. The present review will discuss recent research demonstrating the existence of a period of inadequate acetyl-CoA delivery towards the tricarboxylic acid cycle (the so-called 'acetyl group deficit'), which occurs as a consequence of the impaired integration of cytosolic (glycolysis) and mitochondrial energy producing pathways at the onset of muscular contraction; due to a lag in the activation of the pyruvate dehydrogenase complex. During this period of inadequate acetyl-CoA delivery, acetyl groups can be sequestered from the limited muscular acetylcarnitine reserve in an attempt to sustain continued tricarboxylic acid cycle flux. Following on from this, the present review will highlight the metabolic and functional benefits to be gained by overcoming this period of metabolic inertia, through elevating the concentration of acetylcarnitine prior to physical exercise; in the presence and absence of pyruvate dehydrogenase complex activation and through appropriately timed 'warm-up' exercise.
\end{abstract}

Keywords. Pyruvate dehydrogenase complex; Acetylcarnitine; Metabolic inertia; Acetyl group deficit; Oxidative metabolism.

\section{Introduction}

Carnitine, or 3-hydroxy-4-trimethylammonium butyrate, is a naturally occurring compound ubiquitously found within mammalian tissues which marks the $100^{\mathrm{th}}$ anniversary of its original discovery in skeletal muscle extracts this year [1]. LCarnitine, the biologically effective isomer of carnitine, plays a key role within several cellular energy producing pathways [2]. By way of example, carnitine is essential towards the transport of long-chain fatty acids across the inner-mitochondrial membrane towards their oxidative fate inside the mitochondrial matrix [3], is

\footnotetext{
* E-mail: PARoberts1975@Hotmail.com
} 
important towards the removal of toxic acyl-CoAs from the mitochondria by forming acylcarnitines $[4,5]$, serves as a temporal acetyl group buffer during the oxidation of carbohydrates during periods of increased pathway flux $[6,7]$, and, in accordance with the Hofmeister series, is an osmoprotectant [8]; thus can impact upon cell volume and osmotic stress responses [9]. There is also expanding evidence indicating that $L$-carnitine has more complex functions within the cell, towards the regulation of gene expression $[10,11]$ and the blockage of apoptosis at several stages [12-14]. This review article will focus on the physiological role of the carnitine pool as an acceptor and temporal donator of acetyl groups (in the form of acetyl-CoA) at the immediate onset of muscular contraction and will highlight the beneficial effect of acetylating the carnitine pool prior to muscular contraction upon subsequent contractile performance.

\section{Muscular Carnitine Pool and Fluctuations during Physical Exercise}

A typical $70 \mathrm{~kg}$ omnivore male contains $\sim 21 \mathrm{~g}$ of carnitine, maintained through the concerted actions of an active carnitine biosynthetic pathway in the kidney ( $\sim 30 \%$ of daily requirement), efficient renal reuptake of carnitine from the urine, and from the consumption of carnitine dense foods, i.e., red meats $(\sim 70 \%$ of daily requirement) [15]. Skeletal muscle represents the major storage site of carnitine within the body, accounting for $\sim 90-95 \%$ of the total-carnitine reserve, with free-carnitine the major constitute in resting tissue $(\sim 80 \%)$, with the remainder made up of esterified derivatives (acylcarnitines); products of reactions catalysed by carnitine acyltransferases (Fig. 1). Allied to the dominant distribution of carnitine towards the musculature, there is also a biased distribution of carnitine within the cell, with $\sim 90 \%$ of the carnitine pool existing outside of the mitochondria; possibly to aid the carnitine mediated transport of activated long-chain acyl groups across the mitochondrial membranes $[16,17]$. The intra and extra-mitochondrial carnitine stores are linked by a reversible carnitine acetyltransferase (Fig. 1), which permits the equilibration of mitochondrial derived acetyl groups with the larger cytosolic carnitine pool which can also lead to the acetylation of the limited cytosolic freecoenzyme A pool [18-20].

The composition of the muscular carnitine pool alters acutely and chronically in response to various external factors, ranging from diabetes [21], dietary composition [22], drug interventions [23], renal dialysis treatment [24], to physical exercise [25]. Nowhere is this alteration more profound than during the transition from rest to exercise where the concentration of acetylcarnitine can increase upto 5-fold and account for $\sim 95 \%$ of the total-carnitine pool within the muscle [26]. Indeed, during moderate to intense skeletal muscle contraction acetylcarnitine has been shown to accumulate almost linearly with time [6,25], with the rate of accumulation being greater with increasing exercise intensity [26] and under conditions of reduced blood flow (ischaemia) [27, 28] and oxygen availability (hypoxia) [29]. The ability of free-carnitine to accept excess acetyl-CoA, when produced by the pyruvate dehydrogenase complex in excess of the demands of the tricarboxylic acid cycle, is critical given that the total store of free-coenzyme A within the muscle is relatively small ( $\sim 50-60 \mu \mathrm{mol} \mathrm{kg}^{-1}$ dry muscle) [30], with $95 \%$ of this store confined to the mitochondria with the remainder existing extra-mitochondrially [31]. Indeed, 


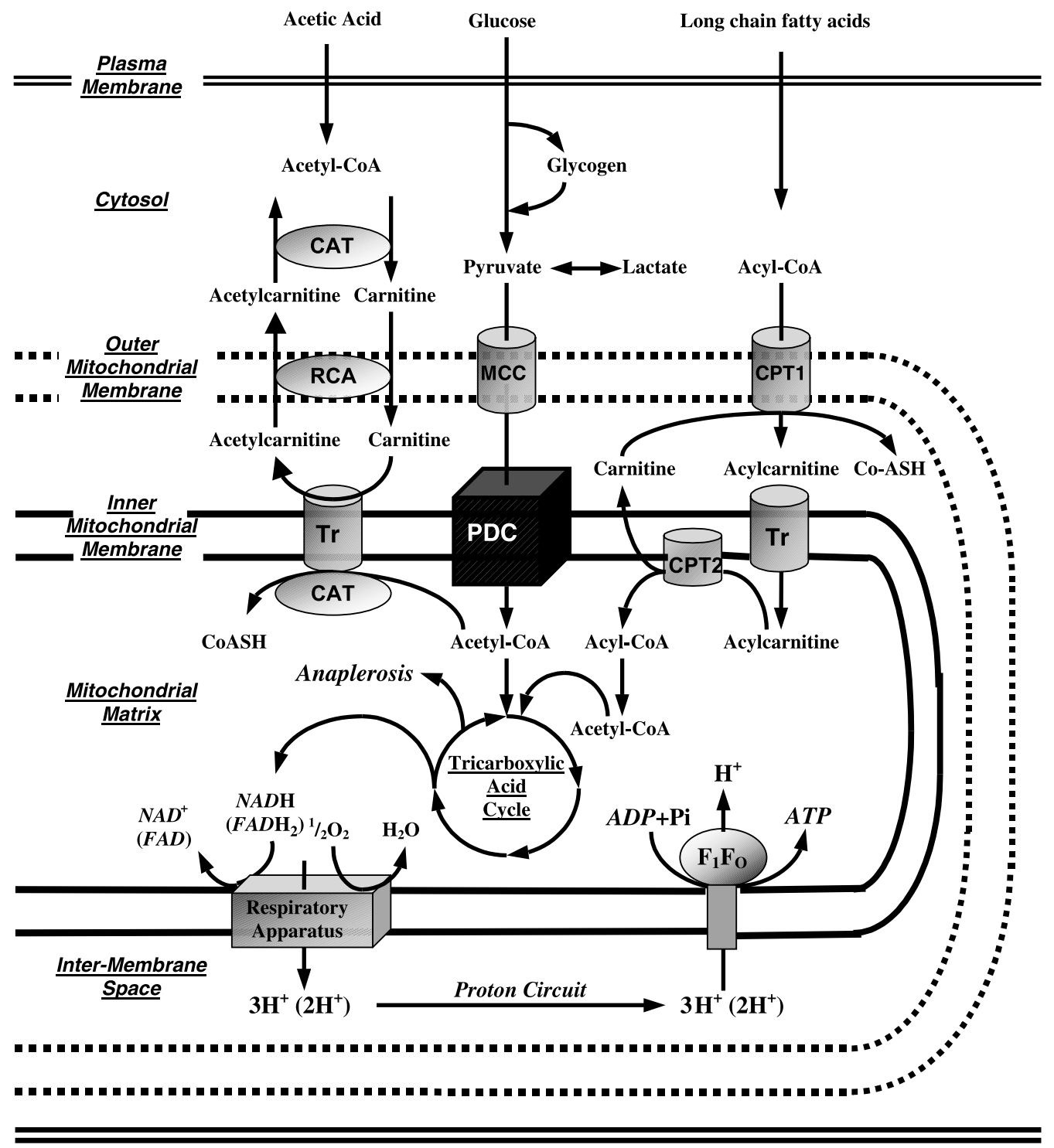

Fig. 1. Carnitine, the pyruvate dehydrogenase complex (PDC), and their location within the major metabolic pathways; the PDC is depicted as a black-box in the centre of the diagram; Key: CAT = carnitine acetyltransferase; $\mathrm{RCA}=$ reversible carnitine acetyltransferase; $\mathrm{MCC}=$ monocarboxylic carrier; $\mathrm{CPT} 1=$ carnitine palmitoyl-transferase 1 ; CPT2 = carnitine palmitoyl-trasnferase $2 ; \operatorname{Tr}=$ translocase; $\mathrm{F}_{1} \mathrm{~F}_{0}=\mathrm{F}_{1} \mathrm{~F}_{0}$ ATPase

without the creation of this reservoir of 'active acetyl groups' in the form of acetylcarnitine, the increased flux through the pyruvate dehydrogenase complex at the onset of contraction would acetylate the entire free-coenzyme A reserve within just a few seconds, leading to the immediate cessation of flux through the pyruvate dehydrogenase complex. The question arises as to why acetylcarnitine accumulates, and more specifically why does acetyl-CoA (produced via the pyruvate dehydrogenase complex reaction) accumulate in excess of the requirements of the tricarboxylic acid cycle? This lack of metabolic efficiency [32] could be 
in part attributable to the evolutionary history of the mitochondria [33, 34], due to carnitine acyltransferase competing more successfully for the available acetyl-CoA than citrate synthase at the immediate onset of exercise or possibly exists as a mechanism by which the energy demand of muscular contraction can be repaid following exercise, when pyruvate dehydrogenase complex derived acetyl-CoA delivery to the mitochondria is markedly reduced to preserve carbohydrate reserves. By way of example, following physical exertion the accumulated acetylcarnitine slowly declines back to its basal concentration as acetyl groups are sequestered from this store to produce ATP and to replenish the phosphocreatine store. Based on the almost linear increase in acetylcarnitine during exercise it has been inferred that acetyl-CoA availability matches or is in excess of tricarboxylic acid cycle requirements throughout contraction, although recent evidence has cast doubt upon this inference [7]; a point I will return to later in the text.

Recently it has been observed that the concentration of acetylcarnitine can decline during the first minute of contraction under conditions where the muscular carnitine reserve had been near-maximally acetylated to acetylcarnitine through pharmacological intervention [28]. This study raised, for the first time, the possibility that if the availability of acetyl groups (in the form of acetylcarnitine or acetyl-CoA) could be increased prior to muscular exertion, then this extra substrate reserve could be utilised during subsequent contraction [28]. I will return to the subject of acetylcarnitine utilisation during muscular contraction later in this review.

\section{Mitochondrial Energy Production at the Onset of Exercise - 'The Oxygen Deficit'}

At the onset of contraction a step-increase in the demand for free-energy, in the form of $A T P$, is put in place by skeletal muscle. As the store of ATP within the cell is limited $\left(\sim 25 \mathrm{mmol} \mathrm{kg}^{-1}\right.$ dry muscle), pathways to regenerate ATP must be rapidly activated to maintain both contractile function and cellular homeostasis. It is a remarkable feature therefore that during contraction, at all but the highest of intensities, the cellular concentration of ATP remains fairly constant. The increase in demand for ATP cannot be met solely by oxygen-dependent ATP re-synthesis at the onset of contraction, whose activation is delayed and follows an approximately exponential time-course [35].

During this period of latency, the transient shortfall in mitochondrial-ATP production, classically termed the 'oxygen deficit' [36, 37], is supplemented by ATP re-synthesis from oxygen independent routes (i.e., ATP and phosphocreatine breakdown and lactate formation) [38-42]. By way of example, Bangsbo et al. [41] observed that phosphocreatine hydrolysis and lactate accumulation collectively contributed $\sim 80 \%$ of the total ATP generated during the initial $30 \mathrm{~s}$ of highintensity exercise. This figure declined to $\sim 45 \%$ from $60-90 \mathrm{~s}$ and to $\sim 30 \%$ after $120 \mathrm{~s}$ of exercise, and appeared to be accompanied by a parallel increase in mitochondrial ATP delivery. Although ATP production from oxygen-independent routes enables rapid rates of $A T P$ turnover to be achieved, it has only a finite capacity and also results in the accumulation of metabolic by-products that are deleterious to muscular contractile function (hydrogen ions, lactate ions, and inorganic 
phosphate) [43]. Indeed, without the progressive increase in mitochondrial ATP production at the onset of contraction, and thereby the reduction in energy delivery via oxygen-independent routes, the onset of muscular fatigue would be markedly accelerated.

Classically, the lag in oxygen-dependent (mitochondrial) ATP re-synthesis at the onset of contraction, and the resulting activation of oxygen-independent ATP regeneration, has been attributed to an impaired rate of increase, or inertia, in skeletal muscle blood flow and thereby oxygen delivery towards the contracting muscle fibres [44-47]. Indeed, the temporal changes in muscle oxygen utilisation at the onset of exercise closely follow the increase in total limb blood flow during this period; hence the general acceptance of the phrase 'oxygen deficit' within the literature $[36,37]$. Over the past decade, however, there has been a growing body of evidence indicating that neither muscle blood flow (bulk oxygen delivery) nor capillary diffusion limit oxygen utilisation at the onset of exercise, such that the true physiological genesis of the lag in oxidative ATP resynthesis remains open to debate [35, 48, 49].

\section{Metabolic Inertia - 'The Acetyl Group Deficit'}

Work by Grassi and colleagues investigating blood flow and oxygen uptake kinetics at the onset of upright cycling exercise in humans noted an increase in venous oxygen content during the first $15 \mathrm{~s}$ of contraction at a time when calculated leg oxygen uptake was minimal, indicating that oxygen delivery was in excess of oxygen demand at the very onset of contraction [50]. In a recent series of studies, within an isolated and perfused canine gastrocnemius muscle model, Grassi and co-workers demonstrated that elimination of the delay in oxygen delivery at the onset of contraction, by keeping blood flow elevated did not affect the kinetics of muscle oxygen consumption during sub-maximal contraction [51], but did result in faster oxygen uptake by the muscle at a maximal exercise workload and a $\sim 25 \%$ reduction in the calculated oxygen-deficit [52]. These findings suggest that mitochondrial ATP re-synthesis is not limited by convective blood flow, and thereby oxygen delivery, during transitions from rest to sub-maximal workloads [51]. They concluded that the limitations to the rate of increase in mitochondrial ATP resynthesis at the onset of exercise are likely attributable to heterogeneous microvascular oxygen delivery and/or an intrinsic inertia within mitochondrial energy production of unspecified origin.

Work within the laboratory of Prof. Paul Greenhaff (Nottingham, UK) over the past decade has investigated the pyruvate dehydrogenase complex as a potential site of limitation towards mitochondrial ATP re-synthesis at the immediate onset of muscular contraction $[7,27,28,53-56]$. The pyruvate dehydrogenase complex (PDC) is a multi-enzyme complex, located on the mitochondrial inner membrane, which regulates carbohydrate entry into the tricarboxylic acid cycle. The PDC catalyses the physiologically irreversible reaction that commits carbohydrates to their oxidative fate inside the mitochondria through the conversion of the glycolytic product pyruvate into mitochondrial acetyl-CoA (involving $N A D^{+}$and free-coenzyme A as substrates, Fig. 2). Regulation of the rate of formation of acetyl-CoA by the PDC (i.e., flux through the enzyme complex) is achieved by two strategies. The first 
Pyruvate $+\mathrm{NAD}^{+}+\mathrm{CoASH} \longrightarrow$ Acetyl-CoA $+\mathrm{NADH}^{+}+\mathrm{H}^{+}+\mathrm{CO}_{2}$

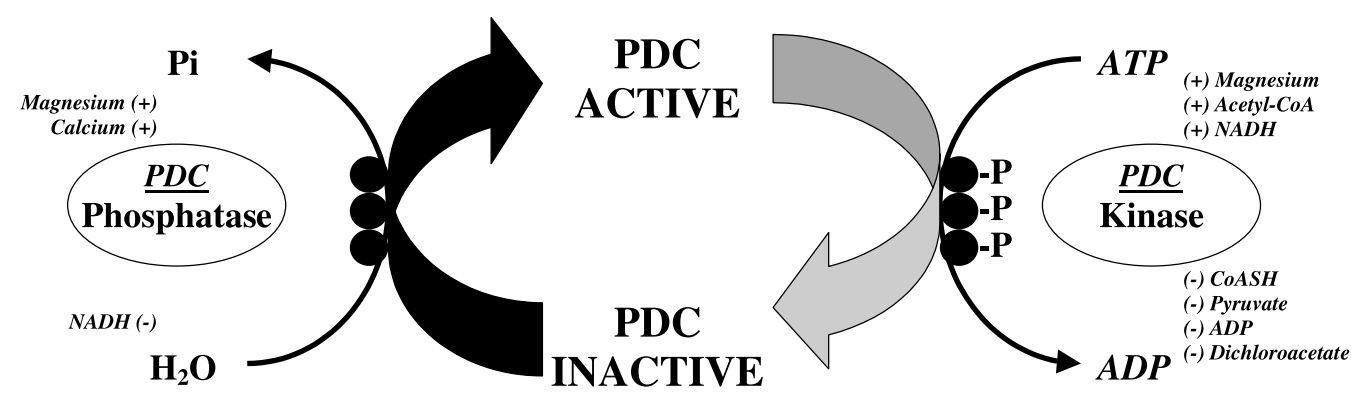

Fig. 2. The pyruvate dehydrogenase complex reaction and covalent regulation of activation status by the intrinsic pyruvate dehydrogenase phosphatase and kinase system; CoASH = free-coenzyme A; $\mathrm{Pi}=$ inorganic phosphate; $(-)=$ an inhibitor of the enzyme it is beside; $(+)=$ an activator of the enzyme it is beside; $\mathrm{P}=$ phosphorylation of the three specific serine residues upon the haloenzyme core of the pyruvate dehydrogenase complex (PDC); Dichloroacetate = systemic pyruvate dehydrogenase kinase inhibitor sodium dichloroacetate

of these is by altering the fraction of PDC that exists in its active form. This is achieved by covalent modification of PDC, either from its inactive (phosphorylated) to active (dephosphorylated) state by loosely associated pyruvate dehydrogenase phosphatases, or vice versa by a number of intrinsic and tissue specific pyruvate dehydrogenase kinases (Fig. 2) [57, 58]. These effectors of PDC activation are sensitive to changes in calcium availability, cellular energetics, and substrate/ product accumulation $[59,60]$. Secondly, the rate of pyruvate oxidation by PDC is regulated by end-product inhibition of flux through the enzyme complex by NADH and acetyl-CoA (Fig. 2) [57]. The acetyl groups produced by PDC can be utilised by the tricarboxylic acid cycle or, alternatively, can be stockpiled in the form of acetylcarnitine, presumably when acetyl-CoA re-synthesis exceeds its rate of utilisation by citrate synthase [6]. Therefore, the muscular carnitine pool can be viewed as an indirect stimulator of PDC flux (and thereby carbohydrate metabolism), through the maintenance of a viable pool of free-coenzyme A for sustained tricarboxylic acid cycle flux (Fig. 2).

In a landmark study by Timmons and co-workers in 1996 [53], pharmacological activation of the PDC, using the systemic PDC kinase (PDK) inhibitor dichloroacetate (Fig. 2) [61, 62], markedly increased acetylcarnitine availability in resting skeletal muscle and appreciably reduced phosphocreatine hydrolysis and lactate accumulation during subsequent intense contraction and under conditions where muscle blood flow and oxygen delivery were fixed at close to resting levels. Following on from this work, the Greenhaff group demonstrated in both canine and human skeletal muscle that the rapid hydrolysis of phosphocreatine and accumulation of lactate that occurs at the onset of exercise was at least partially due to an inherent lag in the activation of oxygen-dependent (mitochondrial) ATP regeneration $[28,54]$. In particular, they were able to show that activation of the PDC at rest, using dichloroacetate, was accompanied by $\sim 30 \%$ reduction in ATP re-synthesis from oxygen-independent routes after 1 min of contraction, even though muscle force production was identical to the saline treated (control) group. Following 
6 min of contraction, the contribution from oxygen-independent routes to ATP resynthesis had fallen to $\sim 50 \%$ of that observed in the control group, while tension development was maintained much better [28]. It also appeared from these studies that some of the acetyl groups that were stockpiled at rest after PDC activation were utilised during contraction, indicating that the mitochondria were able to utilise more acetyl groups at the onset of exercise when provision was increased by dichloroacetate administration $[28,53]$. From these investigations, it was concluded that the activation, and thereby flux, through PDC must limit acetyl-CoA availability and consequently mitochondrial ATP re-synthesis at the onset of exercise. Moreover, that the activation of PDC and 'priming' of mitochondria with acetyl groups prior to exercise, by administering dichloroacetate, could significantly increase the overall contribution of oxidative pathways to total ATP production at the onset of exercise. Another important finding from this series of studies was that the decline in muscle tension development during contraction (i.e., fatigue) was substantially reduced following dichloroacetate administration, most probably due to phosphocreatine hydrolysis and lactate accumulation being reduced at the immediate onset of contraction [28, 53]. Furthermore, this effect was sustainable throughout contraction, at least until the exercise workload was increased to a near maximal intensity [54].

If inertia in the rate of increase in oxygen-dependant ATP regeneration at the onset of exercise does indeed reside at the level of PDC, which the work of Timmons et al. [28] certainly seems to indicate, then it stands to reason that a period of time must exist at the onset of exercise when acetyl-CoA supply via PDC is insufficient to match the demands of the tricarboxylic acid cycle, and the concentration of acetyl-CoA should therefore decline. However, studies to date have shown that acetyl groups appear to accumulate throughout moderate-tointense muscular contraction [6, 25, 27, 63]. From these findings, it has been inferred that acetyl-CoA production is probably in excess of tricarboxylic acid cycle demands throughout contraction, which contrasts with the generated hypothesis that metabolic inertia resides at the level of PDC. Closer scrutiny of the relevant literature reveals, however, that studies to date have failed to investigate the metabolic events occurring within the initial seconds of contraction, or indeed, at any time-point during contraction prior to significant PDC activation. Roberts et al. comprehensively addressed this issue in 2002, in a study designed to conclusively address the issue of acetyl group availability at the immediate onset of contraction [7]. Using a canine hind-limb perfusion model, five muscle biopsy samples were obtained from the gracilis muscle during the first minute (rest, 10, 20, 40, and 60s) of ischaemic muscle contraction, which was envisaged to give sufficient resolution to elucidate the temporal relationship between PDC activation, acetyl group accumulation, and phosphocreatine hydrolysis and lactate accumulation at the onset of contraction [7]. The results demonstrated that a lag in acetyl group provision (in the form of acetyl-CoA and acetylcarnitine) occurred during the initial $20 \mathrm{~s}$ of contraction, which resulted from, and was mirrored by, a lag in PDC activation (Control, Fig. 3). This unequivocally demonstrated the existence of a period of metabolic inertia (the so called 'acetyl group deficit') in skeletal muscle at the onset of contraction [7] and has been supported by further studies [56, 64]. Although the lag in acetyl-CoA and acetylcarnitine accumulation is only temporal 

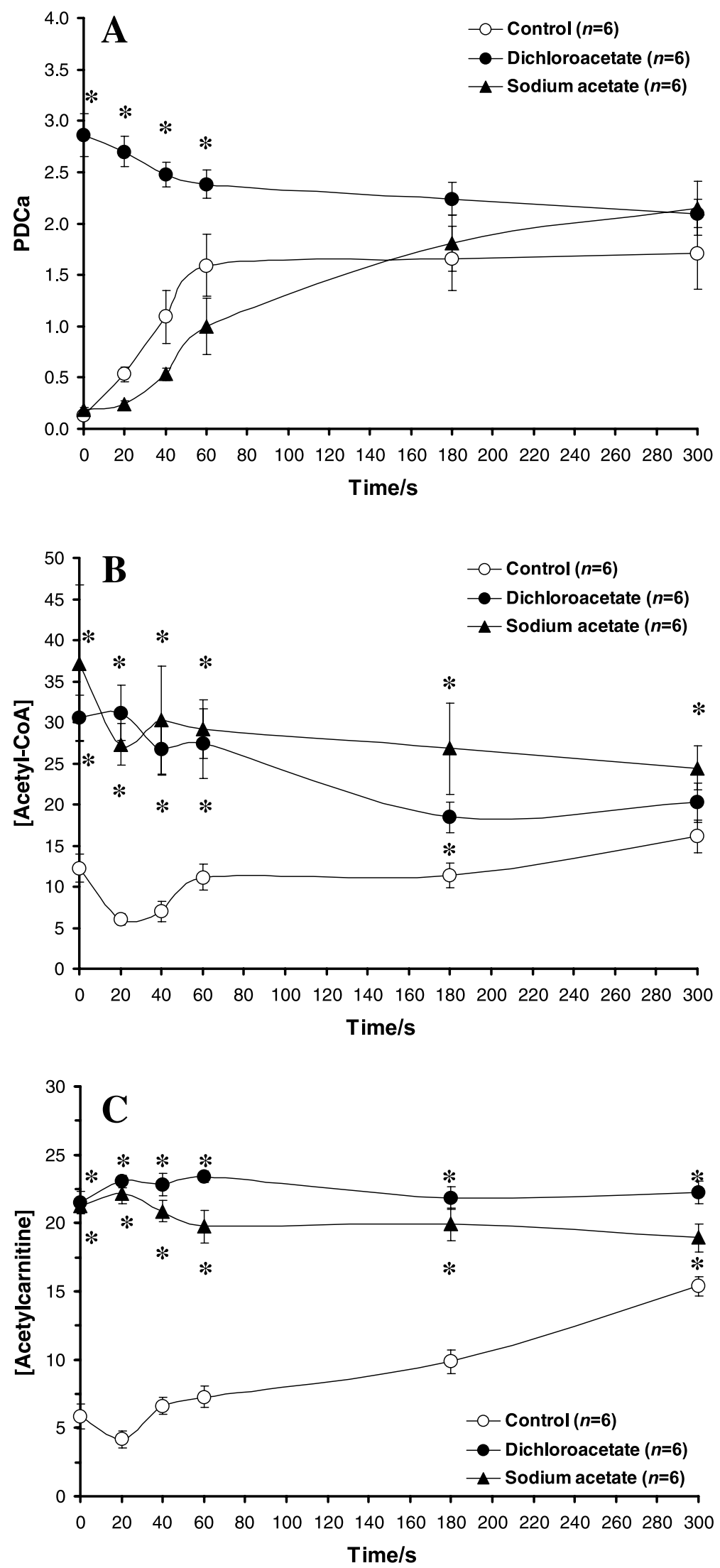
and the numerical decline in their respective concentrations is only small, it is important to recognise that the units on the $y$-axis of the acetylcarnitine graph (Fig. 3C) are 1000-fold higher (mmol) than that of the acetyl-CoA $(\mu \mathrm{mol})$ graph (Fig. 3B). Furthermore, it is important to recognise that $1 \mathrm{mmol}$ of acetyl groups (in the form of acetylcarnitine and acetyl-CoA) is stoichiometrically identical to $12 \mathrm{mmol}$ of ATP equivalents being produced by the electron transport machinery; in response to the entrance of a single acetyl-CoA moiety into the tricarboxylic acid cycle and the generation of $1 \times G T P, 3 \times N A D H$, and $1 \times F A D \mathrm{H}_{2}$ with each turn of the cycle. So clearly, a small decline in acetylcarnitine concentration can have a profound effect upon the amount of energy production required from the limited oxygen independent routes.

As dichloroacetate activates the PDC and near maximally acetylates the freecoenzyme A and carnitine pools at rest (Dichloroacetate, Fig. 3), it was not possible to determine in any of our previous studies whether the reduction in oxygenindependent ATP re-synthesis at the onset of contraction following dichloroacetate treatment (Dichloroacetate, Fig. 4) was attributable to acetyl-CoA delivery via the PDC being increased at the immediate onset of contraction (Dichloroacetate,

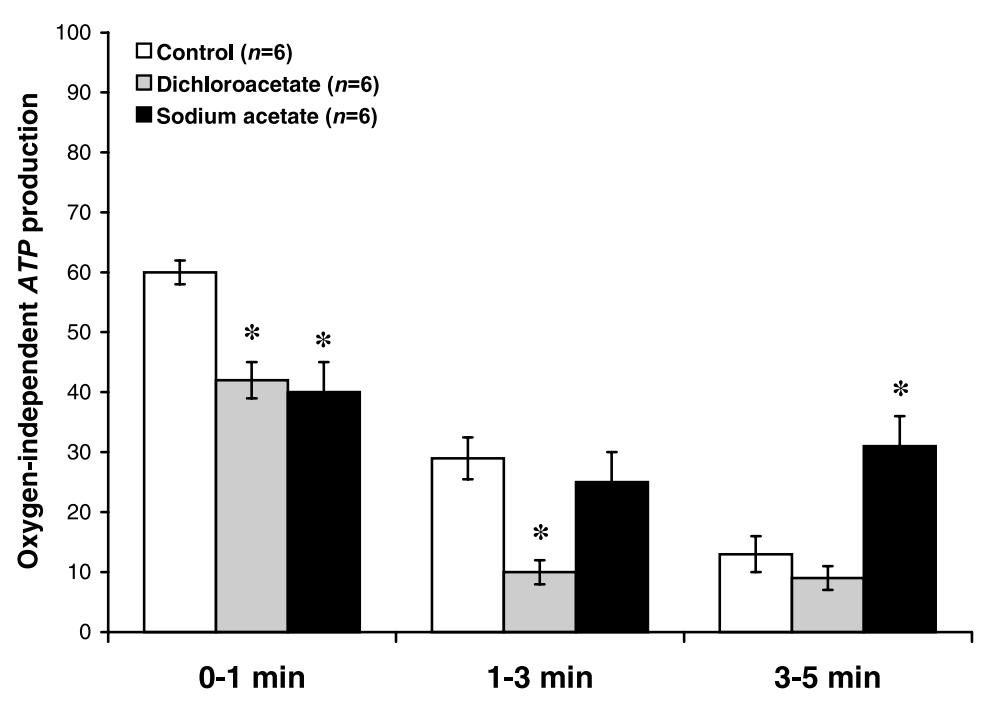

Fig. 4. Rates of ATP re-synthesis from oxygen independent routes (phosphocreatine and ATP degradation and lactate accumulation) between rest and $1 \mathrm{~min}, 1$ and $3 \mathrm{~min}$, and 3 and $5 \mathrm{~min}$ of ischaemic contraction following pre-treatment with control (white), sodium dichloroacetate (grey), and sodium acetate (black); results are expressed as means \pm SEM, with units of mmol of ATP equivalents $\mathrm{min}^{-1} \mathrm{~kg}^{-1}$ dry muscle; ${ }^{*}$ significantly different from corresponding control value $(p<0.05)$

Fig. 3. Active form of the pyruvate dehydrogenase complex (PDCa) and acetyl-CoA and acetylcarnitine concentrations at rest and during $5 \mathrm{~min}$ of ischaemic contraction following pre-treatment with control (open circles), sodium dichloroacetate (closed circles), and sodium acetate (closed triangles); units are as follows: PDCa, mmol of acetyl-CoA $\mathrm{min}^{-1} \mathrm{~kg}^{-1}$ dry muscle (at $37^{\circ} \mathrm{C}$ ); acetyl-CoA, $\mu \mathrm{mol} \mathrm{kg}^{-1}$ dry muscle; acetylcarnitine, $\mathrm{mmol} \mathrm{kg}^{-1}$ dry muscle; results are expressed as means \pm SEM; ${ }^{*}$ significantly different from corresponding control value $(p<0.05)$ 
Fig. 3A) and/or was due to the readily available pool of acetyl groups being sequestered by the tricarboxylic acid cycle (Dichloroacetate, Figs. 3B, 3C). With this question in mind, we have recently investigated whether pharmacologically increasing the availability of acetyl-CoA and acetylcarnitine, independent of PDC activation, could overcome the 'acetyl group deficit' at the onset of exercise [56]. We were able to show that administration of sodium acetate increased the availability of acetyl-CoA (Sodium acetate, Fig. 3B) and acetylcarnitine (Sodium acetate, Fig. 3C) in resting skeletal muscle, but did not increase PDC activation (Sodium acetate, Fig. 3A). Furthermore, during the first minute of ischaemic muscle contraction, when the PDC was largely inactive (Sodium acetate, Fig. 3A), treatment with sodium acetate increased the contribution of oxygen-dependent ATP regeneration towards the energy demands of the muscle when compared to the saline treated (control) group (Fig. 4) [56]. However, following this first minute, when near maximal activation of PDC had been achieved in both control and acetate groups (Fig. 3A), it appeared that PDC derived acetyl-CoA, rather than stockpiled acetyl groups per se, was the principal route of substrate delivery to the tricarboxylic acid cycle. Collectively these investigations have established the activation of the pyruvate dehydrogenase complex as a rate limiting step in the rate of rise in oxygendependent ATP production in skeletal muscle at the onset of exercise, which in turn will dictate the magnitude of oxygen-independent $A T P$ delivery and thereby the rate of fatigue development.

\section{Warm-up Exercise and Carnitine}

A period of low-intensity exercise, commonly referred to as 'warm-up' exercise, has been shown to have a range of physiological and biochemical benefits upon performance during a subsequent bout of exercise [65-68]. These benefits have been classically attributed to exercise-induced elevations in muscle temperature and blood (oxygen) delivery prior to the onset of a second bout of more intense exercise. As stated previously, acetylcarnitine accumulates during muscular contraction before gradually returning to its basal concentration upon the cessation of exercise; as the accumulated acetyl groups are sequestered back towards the tricarboxylic acid cycle (via the carnitine acyltransferase reaction, Fig. 1), to repay the energy cost of contraction (principally through $\mathrm{PCr}$ re-synthesis). Therefore, and in light of the findings discussed above, a period of low-intensity ('warm-up') exercise, of sufficient duration to elevate muscular acetylcarnitine stores, could positively impact upon the rate of onset of oxidative ATP re-synthesis and performance within a second bout of more strenuous (prolonged) physical exercise, performed several minutes later. This hypothesis was recently tested by Campbell-O'Sullivan et al. [55] where a group of healthy male subjects performed 10 min of exercise at $75 \%$ maximal oxygen uptake $\left(\mathrm{VO}_{2} \max \right)$ in the presence and absence of $10 \mathrm{~min}$ of warm-up exercise $\left(55 \% \mathrm{VO}_{2}\right.$ $\max$, with a 3 min rest between bouts. Warm-up exercise elevated muscle acetylcarnitine by $\sim 4 \mathrm{mmol} \mathrm{kg}^{-1}$ dry muscle from basal prior to the start of the second bout of exercise, independent of any alteration in resting blood flow, ATP, phosphocreatine, and glycogen concentrations, and was associated with $\sim 40 \%$ reduction in the requirement for oxygen-independent $A T P$ re-synthesis [55]. Collectively these results suggest that the 'acetyl group deficit' at the immediate onset of contraction can be 
overcome by appropriately timed warm-up exercise via an envisaged increased onset of mitochondrial ATP re-synthesis [55].

\section{Conclusions and Future Perspectives}

In conclusion, I hope the present review has provided convincing evidence to support the contention that pyruvate dehydrogenase complex activation, and thereby acetyl-CoA availability, is limiting towards mitochondrial (oxidative) ATP resynthesis at the immediate onset of contraction, resulting in the sequestering of acetyl groups from the limited mitochondrial acetylcarnitine reserve. Increasing the concentration of acetylcarnitine prior to exercise, either directly (with sodium acetate), via the activation and increased flux through the pyruvate dehydrogenase complex (dichloroacetate), or through the performance of appropriately timed 'warm-up' exercise can overcome the 'acetyl group deficit' and accelerate the onset of mitochondrial ATP re-synthesis. The consequences of this are a marked reduction in $A D P / A M P$ mediated phosphocreatine and glycogen degradation and lactate formation resulting in a subsequent improvement in the maintenance of contractile function. Based on this evidence, any strategy that can 'prime' the mitochondria or increase their responsiveness towards a step-increase in energy demand upon the initiation of muscular contraction, can be expected to be a novel therapeutic target towards the treatment of clinical conditions where premature fatigue development is prevalent; such as peripheral vascular disease.

In addition, it remains to be established if dietary $L$-carnitine supplementation can elevate the muscular carnitine pool in man and thereby elevate the absolute availability of acetylcarnitine prior to the onset of exercise. This desire is complicated by the fact that the additional acetylcarnitine would need to be readily available towards the tricarboxylic acid cycle (i.e., predominantly located inside the mitochondria) [32] and due to the difficulty in elevating the total-carnitine pool (especially within skeletal muscle) through prolonged carnitine supplementation in healthy (omnivore) humans [69]. Experiments targeted to address this issue will need to wait until technological advancements in tissue specific and organelle specific drug delivery systems have been perfected.

\section{Acknowledgements}

The Author would like to acknowledge AstraZeneca Pharmaceuticals, the British Heart Foundation, and the Medical Research Council for their support of the work outlined in this review article. The Author would also like to acknowledge the contributions of his co-workers and colleagues (as detailed in the original publications), and Lonza Ltd., Basel, Switzerland for supporting this article.

\section{References}

[1] Gulewitsch WKR, Krimberg R (1905) Hoppe-Seyler's Z Physiol Chem 45: 326

[2] Bremer J (1983) Physiol Rev 63: 1421

[3] Fritz I (1955) Acta Physiol Scand 34: 367

[4] Brass EP, Hoppel CL (1980) Biochem J 190: 495

[5] Bieber LL, Emaus R, Valkner K, Farrell S (1982) Fed Proc 41: 2858

[6] Childress CC, Sacktor B, Traynor DR (1966) J Biol Chem 242: 754 
[7] Roberts PA, Loxham SJG, Poucher SM, Constantin-Teodosiu D, Greenhaff PL (2002a) J Physiol 544: 591

[8] Hofmeister F (1888) Arch Exp Pathol Pharmak 24: 247

[9] Peluso G, Barbarisi A, Savica V, Reda E, Nicolai R, Benatti P, Calvani M (2000) J Cell Biochem 80: 1

[10] Giovenali P, Fenocchio D, Montanari G, Cancellotti C, D'Iddio S, Buoncristiani U, Pelagaggia M, Ribacchi R (1994) Kidney Int 46: 1616

[11] Horiuchi M, Kobayashi K, Masuda M, Terazono H, Saheki T (1999) Biofactors 10: 301

[12] Andrieu-Abadie N, Jaffrezou JP, Hatem S, Laurent G, Levade T, Mercaider JJ (1999) FASEB J 13: 1501

[13] Mutomba MC, Yuan H, Konyavko M, Adachi S, Yokoyama CB, Esser V, McGarry JD, Babior BM, Gottlieb RA (2000) FEBS Lett 478: 19

[14] Vescovo G, Ravara B, Gobbo VM, Angelini A, Della Barbera M, Dona M, Peluso G, Calvani M, Mosconi L, Dalla Libera L (2002) Am J Physiol 283: C802

[15] Brass EP (1995) Clin Ther 17: 176

[16] Fritz IB, Yue KTN (1963) J Lipid Res 4: 279

[17] Fritz IB, Marquis NR (1965) Proc Natl Acad Sci 54: 1226

[18] Pande SV, Parvin R (2004) J Biol Chem 251: 6683

[19] Newsholme EA, Leech AR (1983) Biochemistry for the Medical Sciences. Wiley, New York, p 110

[20] Lysiak W, Lilly K, Toth PP, Bieber L (1988) Nutrition 4: 215

[21] Mamoulakis D, Galanakis E, Dionyssopoulou E, Evangeliou A, Sbyrakis S (2004) J Diabetes Complications 18: 271

[22] Tsintzas K, Williams C, Constantin-Teodosiu D, Hultman E, Boobis L, Greenhaff P (2000) Exp Physiol 85: 581

[23] Spaniol M, Kauffman P, Beier K, Wüthrich J, Török M, Scharnagl H, März W, Krähenbühl S (2003) J Lipid Res 44: 144

[24] Evans A (2003) Am J Kidney Dis 41: S13

[25] Harris RC, Foster CVL, Hultman E (1987) J Appl Physiol 63: 440

[26] Howlett RA, Parolin ML, Dyck DJ, Hultman E, Jones NL, Heigenhauser GJF, Spriet LL (1998) Am J Physiol 275: R418

[27] Timmons JA, Poucher SM, Constantin-Teodosiu D, Worrall V, Macdonald IA, Greenhaff PL (1996a) Am J Physiol 270: E400

[28] Timmons JA, Poucher SM, Constantin-Teodosiu D, Macdonald IA, Greenhaff PL (1997) Am J Physiol 273: E233

[29] Parolin ML, Spriet LL, Hultman E, Hollidge-Horvat MG, Jones NL, Heigenhauser GJ (2000) Am J Physiol 278: E522

[30] Constantin-Teodosiu D, Carlin JI, Cederblad G, Harris RC, Hultman E (1991) Acta Physiol Scand 143: 367

[31] Idell-Wenger JA, Grotyohann LW, Neeley JR (1978) J Biol Chem 254: 4310

[32] Roberts PA, Loxham SJG, Poucher SM, Constantin-Teodosiu D, Greenhaff PL (2002b) J Physiol 545: 297

[33] Dyall SD, Johnson PJ (2000) Curr Opin Microbiol 3: 404

[34] Roberts PA, Loxham SJG, Poucher SM, Constantin-Teodosiu D, Greenhaff PL (2002b) J Physiol 545: 297

[35] Tschakovsky ME, Hughson RL (1999) J Appl Physiol 86: 1101

[36] Margaria R, Edwards HT, Hill DB (1933) Am J Physiol 106: 689

[37] Saltin B (1990) Anaerobic Capacity: Past, Present, and Prospective. In: Taylor AW, Gollnick PD, Green HJ, Ianuzzo CD, Noble EG, Metivier G, Sutton JR (eds) Biochemistry of Exercise VII. Human Kinetics, Champaign, IL 387 
[38] Hultman E (1967) Scand J Clin Lab Invest 19: 1

[39] Connett RJ, Gayeski TEJ, Honig CR (1984) Am J Physiol 246: H120

[40] Meyer RA, Sweeney HL, Kushmerick MJ (1984) Am J Physiol 246: C365

[41] Bangsbo J, Gollnick PD, Graham TE, Juel C, Kiens B, Mizuno M, Saltin B (1990) J Physiol 422 : 539

[42] Bangsbo J, Graham TE, Kiens B, Saltin B (1992) J Physiol 451: 205

[43] Fitts RH (1994) Physiol Rev 74: 49

[44] Knight DR, Schaffartzik W, Poole DC, Hogan MC, Bebout DE, Wagner PD (1993) J Appl Physiol 75: 2586

[45] Richardson RS, Knight DR, Poole DC, Kurdak SS, Hogan MC, Grassi B, Wagner PD (1995) Am J Physiol 268: H1453

[46] MacDonald M, Pederson PK, Hughson RL (1997) J Appl Physiol 83: 1318

[47] Richardson RS, Grassi B, Gavin TP, Haseler LJ, Tagore K, Roca J, Wagner PD (1999) J Appl Physiol 86: 1048

[48] Grassi B (2001) Exerc Sport Sci Rev 29: 134

[49] Hughson RL, Tschakovsky ME, Houston ME (2001) Exerc Sport Sci Rev 29: 129

[50] Grassi B, Poole DC, Richardson RS, Knight DR, Erickson BK, Wagner PD (1996) J Appl Physiol 80: 988

[51] Grassi B, Gladden LB, Stary CM, Wagner PD, Hogan MC (1998) J Appl Physiol 85: 1394

[52] Grassi B, Hogan MC, Kelley KM, Aschenbach WG, Hamann JJ, Evans RK, Patillo RE, Gladden LB (2000) J Appl Physiol 89: 1293

[53] Timmons JA, Poucher SM, Constantin-Teodosiu D, Worrall V, Macdonald IA, Greenhaff PL (1996b) J Clin Invest 97: 879

[54] Timmons JA, Gustafsson T, Sundberg CJ, Jansson E, Hultman E, Kaijser L, ChwalbinskaMoneta J, Constantin-Teodosiu D, Macdonald IA, Greenhaff PL (1998) J Clin Invest 101: 79

[55] Campbell-O’Sullivan SP, Constantin-Teodosiu D, Peirce N, Greenhaff PL (2002) J Physiol 538: 931

[56] Roberts PA, Loxham SJG, Poucher SM, Constantin-Teodosiu D, Greenhaff PL (2004) Am J Physiol (http://ajpendo.physiology.org/cgi/reprint/00441.2003v1)

[57] Wieland OH (1983) Rev Physiol Biochem Pharmacol 96: 124

[58] Bowker-Kinley MM, Davis WI, Wu P, Harris RA, Popov KM (1998) Biochem J 329: 191

[59] Cooper RH, Randle PJ, Denton RM (1975) Nature 257: 808

[60] Constantin-Teodosiu D, Cederblad G, Hultman E (1993) J Appl Physiol 74: 1712

[61] Whitehouse S, Cooper RH, Randle PJ (1974) Biochem J 141: 761

[62] Pratt ML, Roche TE (1979) J Biol Chem 254: 7191

[63] Howlett RA, Heigenhauser GJF, Hultman E, Hollidge-Horvat MG, Spriet LL (1999) Am J Physiol 277: E18

[64] Roberts PA, Loxham SJG, Poucher SM, Constantin-Teodosiu D, Greenhaff PL (2002a) Exp Physiol 87: 489

[65] Martin BJ, Robinson S, Wiegman DL, Aulick LH (1975) Med Sci Sports Exerc 7: 146

[66] Essen B, Kaijser L (1978) J Physiol 281: 499

[67] Genovely H, Stamford BA (1982) Eur J Appl Physiol Occup Physiol 48: 323

[68] Robergs RA, Pascoe DD, Costill DL, Fink WJ, Chwalbinska-Moneta J, Davis JA, Hickner R (1991) Med Sci Sports Exerc 23: 37

[69] Karlic H, Lohninger A (2004) Nutrition 20: 709 